Chen, X. (2016). Evaluating Language-learning Mobile Apps for Second-language Learners. Journal of

Educational Technology Development and Exchange, 9(2), 39-51.

\title{
Evaluating Language-learning Mobile Apps for Second-language Learners
}

\author{
Xiaojun Chen \\ St. John's University
}

\begin{abstract}
As mobile technologies become more affordable and more advanced in function, researchers suggest that using mobile apps to assist English language learning are appropriate. This three-step evaluation study (designing a theory-driven rubric, selecting apps, and evaluating the apps) aims to investigate and evaluate the affordances of English language learning mobile apps for adult learners. The results of this evaluation study contribute to the literature of mobile learning targeting adult learners, and also broaden the knowledge body of integrating mobile learning into English Language Learning (ELL) classes.
\end{abstract}

Keywords: mobile learning, language learning, adult learners, apps, evaluation

\section{Introduction}

The demand for non-English speaking population to acquire English language skills has grown with globalization. The number of English learners has increased rapidly worldwide, including those in the United States. The United States has a large number of new immigrants, as it is an immigrant country. Broken down by immigration status, the 2014 survey conducted by the Center for American Progress showed that the foreignborn population was composed of 18.6 million naturalized U.S. citizens and 22.1 million non-citizens in 2012. More than twothirds of recent older immigrants $(71 \%)$ did not speak English well in 2006, compared to just about one-third of long-term older immigrants (31\%). Late-life immigrants with limited English skills depend heavily on family members, putting them at risk of isolation and depression (Wilmoth, 2012). Furthermore, elderly immigrants who have low motivation and confidence to learn English, face challenges in using healthcare and other social services (Leach, 2009). As the number of immigrants has dramatically increased through the decades, some issues 
and debates have inevitably been raised: (a) whether or not immigrants, especially the first generation, should learn English, (b) ways to teach immigrants with little English fluency, and (c) possibilities to incorporate technology into English teaching for those who are skeptical of or have no experience using it.

On the other hand, technology has changed every aspect of human life and language learning is no exception. Technology has ushered a new era of teaching and learning. It makes learning engaging, flexible, and heuristic, and technology also boosts productivity and efficiency (Halverson \& Smith, 2009). Researchers have investigated new approaches of integrating computerassisted programs in language-learning (Chapelle, 2009). Abraham (2008) conducted a meta-analysis study to investigate the effects of computer-mediated glosses in second language learning. Golonka, Bowles, Frank, Richardson, and Freynik (2014) reviewed different types of technologies and their effectiveness in foreign language learning. In this review, they found that computerassisted pronunciation training proves to be effective in improving pronunciation, as well as providing effective feedback. Specifically, in the area of vocabulary learning, Ma and Kelly (2006) designed a computer-supported language learning software to help Chinese university learners of English. Cavus and Ibrahim (2009) designed a study to examine the mobile technology and texting effect in language learning, and they found that "students enjoyed and learned new words with the help of their mobile phone" (p.78). Hwang and Wang (2016) implemented a situated computer game in six graders' English classes in order to test the effectiveness of different guiding strategies in helping students acquire English vocabulary. For reading comprehension, researchers like Liu, Hwang, Kuo, and Li (2014) designed content aware learning environments on mobile platforms for language-learners to advance learners' reading comprehension skills. In the area of improving listening skills, Hsu, Hwang, and Chang (2013) conducted experiments examining the effects of an automatic caption filtering and partial hiding approach to improve college students' listening comprehension. The results of the study showed college students' preferred the proposed approach compared to the conventional approach with full captions. As mobile technologies have become more advanced in functions and affordable, researchers suggest that using mobile apps to assist English learning appears to be appropriate (Hargis, Cavanaugh, Kamali, \& Soto, 2014; Hwang \& Wu, 2014; Lin, 2014; Liu, Navarrete, Maradiegue, \& Wivagg, 2014).

Many studies about integrating technology and mobile learning in language learning has focused on K-12 students (Cheung \& Hew, 2009; Hwang \& Wang, 2016; Liu, Navarrete \& Wivagg, 2014; Sandberg, Maris \& de Geus, 2011) or college students (Cavus and Ibrahim, 2009; Ma \& Kelly, 2006). However, there is a gap in the literature in applying mobile learning to adult language learning. This paper aims to contribute information in bridging this gap. Immigrants from older generations are facing more challenges learning English, and it will be valuable to help them find and use mobile apps that can address their specific learning needs, linguistically and culturally. This also applies to English learners in nonEnglish speaking countries who would like to improve their English language abilities. Thus, the purpose of this study is to evaluate English-learning mobile apps (application software) and their affordances in second language learning, especially on helping adult learners with limited English proficiency acquire English skills. 


\section{Theoretical framework}

This section describes the evaluation framework for this study: (1) evaluating the apps according to theories of language acquisition, and (2) evaluating the apps' pedagogical coherence with focus on content quality and application usability. Two theories of language acquisition, social interactionist theory and Krashen's (1982) affective filter hypothesis, guide the evaluation of efficiency and validity for each selected mobile application. Social interactionist theory helps assess the relevance and cognitive development of the language learning process; Krashen's affective filter hypothesis helps determine whether the app is able to pique users' interest and meet their psychological needs when they are learning a second language.

\subsection{Social Interactionist Theory and Affective Filter Hypotheses}

According to the social interactionist theory, caregivers play a critical role in adjusting languages to facilitate the use of innate capacities for language acquisition. This theory is geared towards first language acquisition, and also has inspired intuitive and natural learning patterns in second language acquisition. Specifically, interactionists study the language that mothers and other caregivers use when caring for infants and young children, paying special attention to the modifications they make during these social interactions to assist children in communication. Based on the social interactionist theory, a well-designed language-learning app would embody the features of interactive guidance given by mothers or other caregivers. Such an app would provide legitimate and comprehensible input of the target language in order to help language learners in acquiring a second language. In addition, similar to the gradual development of children's cognitive skills, adult English-language learners' ability can develop over time with massive and intensive interactions. Therefore, the simulation of the interaction process embodied in an app is a key factor to stimulate learners. Such stimulation can engage learners to access and respond to the contextualized input. Thus, important is to examine whether or not an app is providing feedback or allowing users to self-correct their responses in learning tasks within the app. Based on Krashen's affective filter hypothesis, language learners can be distracted by emotional factors in the language learning process. Krashen suggests that low motivation, low self-esteem, and debilitating anxiety prevent comprehensible input from being used for acquisition. In other words, when the filter is up, it impedes language acquisition. On the other hand, positive affect is necessary for acquisition to take place, but not sufficient on its own. Thus, a welldesigned mobile app would lower the affective filter so that users can actively participate in the given tasks. Such interactions can reduce learners' anxiety and self-consciousness, in addition to enhance the likelihood of learning. Thus, motivation is an important aspect to be considered when evaluating the mobile apps for language learning.

\subsection{Pedagogical Dimension of Mobile Learning}

Mobile apps are designed to provide content to their users, thus the rationale for evaluating such applications would need to be grounded in instructional design theories and frameworks. Reeves (1994) outlined fourteen dimensions in evaluating different forms of computer-based education including: epistemology, pedagogical philosophy, underlying psychology, goal orientation, experiential value, teacher role, program 
flexibility, value of errors, motivation, accommodation of individual differences, learner control, user activity, cooperative learning, and cultural sensitivity. In the past two decades, this evaluation framework provided guidelines for researchers and instructional designers to investigate and develop instructional materials for computerbased programs. This evaluation framework has also been adopted into more specific areas such as educational software and programs (Rodríguez, Nussbaum, \& Dombrovskaia, 2012), distance education (Eskey \& Roehrich, 2013), Massive Online Open Courseware (Admiraal, Huisman, \& Pilli, 2015), and instructional apps (Lee \& Cherner, 2015).

As Smith and Ragan (2004) pointed out examining the content, task, and context of the instructional materials or programs was important. Thus, evaluating the quality of the content provided by apps is important. Given that the apps are for used for learning, it is vital to assess the pedagogy coherence of language skills within the learning activities. Apps are software installed on mobile devices, thus evaluating the usability, customization, and sharing options provided by such app is valuable. In summary, seven elements are identified to evaluate language-learning mobile apps: content quality, pedagogical coherence on language skills, feedback and self-correction, motivation, usability, customization, and sharing. Table 1 below highlights each section of these seven areas.

Table 1. Language-learning Mobile Application Evaluation Rubric

\begin{tabular}{|c|c|c|c|}
\hline Category & Least Suitable (1-3) & Average (4-7) & Most Suitable (8-10) \\
\hline $\begin{array}{l}\text { Content Quality: } \\
\text { Content should } \\
\text { provide opportunities } \\
\text { to advance learners' } \\
\text { English skills, with } \\
\text { connection to their } \\
\text { prior knowledge. }\end{array}$ & $\begin{array}{l}\text { Content fails to help } \\
\text { achieve learning } \\
\text { goals or autonomous } \\
\text { learning. }\end{array}$ & $\begin{array}{l}\text { Content helps } \\
\text { achieve the } \\
\text { learning goals, } \\
\text { but is neither } \\
\text { autonomous } \\
\text { learning nor } \\
\text { related to prior } \\
\text { knowledge. }\end{array}$ & $\begin{array}{l}\text { Content helps achieve } \\
\text { the learning goals, } \\
\text { autonomous learning, } \\
\text { and relating prior } \\
\text { knowledge to new } \\
\text { content. }\end{array}$ \\
\hline $\begin{array}{l}\text { Pedagogical } \\
\text { Coherence: The skills } \\
\text { provided in the app } \\
\text { should be consistent } \\
\text { with the targeted } \\
\text { learning goal. }\end{array}$ & $\begin{array}{l}\text { Skills (especially } \\
\text { listening and speaking } \\
\text { skills) reinforced } \\
\text { in the app were not } \\
\text { consistent to the } \\
\text { targeted skill or } \\
\text { concept. }\end{array}$ & $\begin{array}{l}\text { Skills (especially } \\
\text { listening and } \\
\text { speaking skills) } \\
\text { reinforced were } \\
\text { prerequisite of } \\
\text { foundation skills } \\
\text { for the targeted } \\
\text { skill or concept. }\end{array}$ & $\begin{array}{l}\text { Skills (especially } \\
\text { listening and speaking } \\
\text { skills) reinforced were } \\
\text { strongly connected } \\
\text { to the target skill or } \\
\text { concept. }\end{array}$ \\
\hline
\end{tabular}


Table 1. Language-learning Mobile Application Evaluation Rubric

\begin{tabular}{|c|c|c|c|}
\hline Category & Least Suitable (1-3) & Average (4-7) & Most Suitable (8-10) \\
\hline $\begin{array}{l}\text { Feedback and self- } \\
\text { correction: Learners } \\
\text { should be provided } \\
\text { with feedback } \\
\text { to conduct self- } \\
\text { evaluation. }\end{array}$ & $\begin{array}{l}\text { Feedback is limited } \\
\text { to correct learner } \\
\text { response. }\end{array}$ & $\begin{array}{l}\text { Feedback is specific } \\
\text { and allows for } \\
\text { learners to try again } \\
\text { in order to improve } \\
\text { learning performance. }\end{array}$ & $\begin{array}{l}\text { Feedback is specific, } \\
\text { which results in } \\
\text { improved learners' } \\
\text { performance; data is } \\
\text { available to learners } \\
\text { and instructors. }\end{array}$ \\
\hline $\begin{array}{l}\text { Motivation: Elements } \\
\text { are embedded to } \\
\text { engage and motivate } \\
\text { language learners to } \\
\text { use the app. }\end{array}$ & $\begin{array}{l}\text { No elements are } \\
\text { embedded to } \\
\text { encourage learners' } \\
\text { self-directed } \\
\text { learning. }\end{array}$ & $\begin{array}{l}\text { Limited elements } \\
\text { are embedded to } \\
\text { encourage learners' } \\
\text { self-directed learning. }\end{array}$ & $\begin{array}{l}\text { Elements are } \\
\text { embedded to } \\
\text { encourage learners' } \\
\text { self-directed learning. }\end{array}$ \\
\hline $\begin{array}{l}\text { Usability: Learners } \\
\text { are provided with } \\
\text { clear indicated menus } \\
\text { and icons to easily } \\
\text { navigate through the } \\
\text { app. }\end{array}$ & $\begin{array}{l}\text { Menus and icons } \\
\text { are not clearly } \\
\text { indicated, no on- } \\
\text { screen help and/ } \\
\text { or tutorial are } \\
\text { available, and } \\
\text { learners need } \\
\text { constant help to use } \\
\text { the app. }\end{array}$ & $\begin{array}{l}\text { Menus and icons are } \\
\text { clearly indicated, but } \\
\text { no on-screen help } \\
\text { and/or tutorial are } \\
\text { available. Learners } \\
\text { need to have an } \\
\text { instructor in order to } \\
\text { review how to use the } \\
\text { app. }\end{array}$ & $\begin{array}{l}\text { Menus and icons } \\
\text { are clearly indicated } \\
\text { and on-screen help } \\
\text { and/or tutorial are } \\
\text { available so that } \\
\text { learners can launch } \\
\text { and navigate the app } \\
\text { independently. }\end{array}$ \\
\hline
\end{tabular}

\section{Customization:}

Learners have their individualized needs met including font size and customizable settings to personalize their learning.
Text size can be adjusted according to user's needs, and some customizations are provided.
Text size can be adjusted to suit diverse needs, and customizations and more individualized options are provided. adjusted, and few customizations are provided.
Sharing: Allowing learners to share their learning progress, issues, or concerns in learning.
Limited performance data, or learner's progress is not accessible.
Performance data or learner progress is available in the app, but exporting is limited.
Specific performance summary or learner progress is saved in the app and can be exported to a teacher or an audience. 


\section{Methods}

After establishing the app evaluation rubric in Table 1, three further steps were taken: (1) selecting and categorizing apps, (2) analyzing and describing each app, and (3) evaluating the selected apps with the designed rubric.

The first step is to identify and select English-learning-oriented apps available both at the App Store and Google Play by searching the keyword "ESL." In the App Store, search results yielded 500 apps for "ESL" with 357 of them being free. On Google Play, the

Table 2. Selected Apps, Ratings and Categories registered apps were 250 in total and 232 of them were free to download. Filtered by the reviews and ratings, a total of 7 English learning apps (see Table 2) were selected. Those apps could also be categorized in three groups: (1) vocabulary apps designed as bilingual dictionaries or tools that enhance vocabulary skills,(2) language skills apps designed towards the four modalities of language proficiency (speaking, listening, reading and writing), and (3) entertainment apps featuring interactive content that engage users in informal learning such as movies, songs, and games.

\begin{tabular}{|c|c|c|c|}
\hline App Name & App Store Rating & Google Play Rating & Category \\
\hline $\begin{array}{l}\text { ShanBay Vocabulary } \\
\text { (www.shanbay.com) }\end{array}$ & $\begin{array}{l}5 \text { stars } \\
\text { (15 ratings) }\end{array}$ & $\begin{array}{c}4.5 \text { stars } \\
\text { (4075 reviews) }\end{array}$ & Vocabulary \\
\hline $\begin{array}{l}\text { Youdao Dictionary } \\
\text { (http://dict.youdao.com) }\end{array}$ & $\begin{array}{c}5 \text { stars } \\
\text { (144 ratings) }\end{array}$ & $\begin{array}{c}4.4 \text { stars } \\
\text { (36751 reviews) }\end{array}$ & Vocabulary \\
\hline $\begin{array}{l}\text { Duolingo } \\
\text { (www.duolingo.com) }\end{array}$ & $\begin{array}{c}4.5 \text { stars } \\
\text { (869 ratings) }\end{array}$ & $\begin{array}{c}4.6 \text { stars } \\
(3,251,411 \text { reviews })\end{array}$ & Language Skills \\
\hline $\begin{array}{l}\text { Speak English Fluently } \\
\text { (www.liulishuo.com) }\end{array}$ & $\begin{array}{c}4.5 \text { stars } \\
\text { (197 ratings) }\end{array}$ & $\begin{array}{c}4.2 \text { stars } \\
(10,179 \text { reviews })\end{array}$ & Language Skills \\
\hline $\begin{array}{l}\text { Speak English - Listen, } \\
\text { Speak, Compare }\end{array}$ & $\begin{array}{c}3.5 \text { stars } \\
(29 \text { ratings })\end{array}$ & $\begin{array}{c}4.0 \text { stars } \\
(30,355 \text { reviews })\end{array}$ & Language Skills \\
\hline $\begin{array}{l}\text { BrainPOP Featured Movie } \\
\text { (https://www.brainpop.com) }\end{array}$ & $\begin{array}{l}4.5 \text { stars } \\
\text { (61 ratings }\end{array}$ & $\begin{array}{c}3.7 \text { stars } \\
(14,749 \text { reviews })\end{array}$ & Entertainment \\
\hline $\begin{array}{l}\text { VoiceTube } \\
\text { (https://www.voicetube.com) }\end{array}$ & $\begin{array}{l}4.5 \text { stars } \\
\text { (46 ratings) }\end{array}$ & $\begin{array}{c}4.7 \text { stars } \\
(41,455 \text { reviews })\end{array}$ & Entertainment \\
\hline
\end{tabular}

Note: All ratings were obtained on August 15th 2016. 


\section{Results and Discussion}

In this section, the author describes the analysis of each app and presents the rating for each app according to the rubric.

\subsection{Analysis of the Apps}

4.1.1. Duolingo. Duolingo is a free languagelearning and crowd-sourced text translation platform. As of August 15th2016, Duolingo has provided a wide range of languages in its learning materials including: Romanian, Dutch, Portuguese, Russian, Spanish, Polish, French, Arabic, German, Korean, Greek, Chinese, Hungarian, Turkish, Italian, Czech, Japanese, Hindi, Ukrainian, Vietnamese, English, Indonesian, and Thai.

Duolingo provides extensive writing lessons for novice users and oral practices for advanced users. A dictionary function is embedded in the app. Games are integrated in almost every part of the app to engage learners when learning new words. For example, users would gain "experience points" (XP) as they progress through the learning activities in the apps such as completing a pre-designed lesson. Skills are considered "learned/ accomplished" when the user completes all of the lessons associated with the skill. Users win one point for each correct answer, lose one point for each error, and the lesson is considered passed when they reach 10 points. In addition, Duolingo provides feedback to learners. The app also corrects answers when learners make mistakes in practicing their skills. It additionally provides useful tips for learners to improve their language skills.

4.1.2. Speaking English Fluently (Liu-LiShuo). "Speaking English Fluently," is an English-language learning app designed for Chinese English language learners. As the name suggests, liu-li-shuo focuses on training English-language learners' English speaking skills. It provides conversational practice covering a plethora of topics on different subjects such as business, travelling, shopping, and music. Liu-Li-Shuo features two main modes: practice mode and game mode.

The "practice mode" enables users to voice record themselves reading and listen to materials that have been audio recorded by native speakers of English. Learners can compare their utterances to the modeled pronunciation. The accuracy of intonation and pronunciation are analyzed and marked by the built-in system. Feedback is provided to learners when they make mistakes in practicing. For example, missed or unmatched words/phrases become highlighted in different colors, and auto-suggestions are generated as immediate feedback to learners. Thus, the app allows users to practice with realtime feedback. Help is designed to support learners in becoming familiar with English speech patterns and manners of conversation. In 'practice mode,' language learning happen in contextualized situations by allowing an individual to immerse oneself in real life experiences. However, the app fails to give learners further instructions on how to correct and improve the unmatched words or phrases. As a result, learners who fail many times and still cannot get the pronunciation correct may feel frustrated and demotivated.

The other mode is "challenge mode" where learners choose their preferred topics and engage in a predetermined dialogue. Learners can play different roles in each situation and read aloud the words provided. When learners finish recording the conversation using the script in the app, the app's built-in rating system rates their performance and prompt them with the next challenge if the participants' performance matches the standards of the current level of difficulty. If the current level is not matched, learners are directed back to the practice 
mode. Users can earn participation credit towards badges. In addition, learners can share their ideas and questions with other users. The ranking system has made practice and play more desirable: more frequently the user plays, the higher the user's rank will become. In this case, the app successfully lowers the affective filter (Krashen, 1982) and helps learners to place more effort on language drills both voluntarily and naturally. Last, but not least, menus and icons are clearly indicated within this app; however, the app has limited customizations options available and has no on-screen help or tutorials.

4.1.3. Youdao Dictionary. Youdao Dictionary is a multilingual dictionary app, offering free and instant full text translation services. Collins Cobuild Advanced English-Chinese dictionary is built into the Youdao Dictionary App. The app also offers daily bilingual articles that are broken down by sentences, to help English language learners expand their knowledge on vocabulary, quotes, idioms, Internet buzzwords, and trending stories. Youdao Dictionary is a cloud-based app, so learners can save their progress and seamlessly synchronize their learning process on any available devices anytime. The cloudembedded feature also provides books, forums, and classes for users to "discover" more in-depth content.

The navigation in Youdao Dictionary is sleek and simple. Users can expand their dictionaries according to their needs and choose audio pronunciations. Furthermore, the exemplar sentences embedded in the app offer pronunciations from native speakers, and users can choose their preferred tones and styles in the settings. However, this app provides limited assessment and motivation options, and lacks interactive activities and monitoring mechanisms.
4.1.4. VoiceTube. VoiceTube, as its name suggests, is an app that allows users to learn English via YouTube videos. It boasts a cornucopia of English content with over 15,000 videos including TED talks, TED-ED, CNN News, and more. Content listed in the app is classified into three levels: beginner, intermediate, and advanced. Users can also use key-words to search learning materials. The built-in player and dictionaries are tailored toward Chinese English language learners, where they can check the new words in the subtitles by pressing down the word on the screen for a few seconds in order to review the word later. Learners can pause, fastforward, and rewind the videos. Learners can also change the size of the subtitles and speed of the audio in order to accommodate their current learning level. The learners' process can be recorded. The apps' navigation is clearly displayed, and learners can customize their preferred viewing settings. However, this app fails to offer any assessment or feedback for users to monitor their learning progress, and provides very limited sharing features.

4.1.5. Shanbay Vocabulary. Shanbay Vocabulary is geared towards Chinese English language learners. It enjoys a reputation for its effectiveness in building vocabulary. Users are asked choose a "vocabulary book" geared toward the topics they want to spend time and effort in learning such as the GRE, GMAT, Merriam-Webster's Vocabulary, and Builder. Users also can choose their daily learning plan, for example, "review 100 words, or learn 40 new words," and subsequently the glossaries are divided into groups according to the learner's daily learning plan. The vocabulary learning process has two phases, "self-assessment mode" and "quizzes." In the self-assessment mode, learners are asked to evaluate and rate their familiarity with the word they are learning, so users can filter out the words they have already mastered. When 
finished, learners can log the day's learning progress, where they are then awarded a medal, as a way to motivate continued learning. In quiz mode, users can check their understanding of the words they recently learned, and the app will record the answers to help them monitor their learning progress. Its interface is simple and very easy to navigate. Users can form groups and join communities readily, and they can showcase their learning process and carry out discussion with peers. However, no visuals are used in learning.

4.1.6. Speak English. As described in its selfintroduction, Speak English is an app that helps learners improve their English speaking skills naturally and easily. In the beginning, the app asks the learners to select his/her language among 12 language options. It then reveals tips and illustrates tutorials for using this app based on the language chosen by the learner. Learners can reset the language selection at any time and go through the tutorial again. As far as content in the app, two types of sessions are offered for beginners and advanced speakers respectively. Beginner sessions provide basic pronunciation lessons and drills using simple phrases. It also covers numbers, times, and dates. Basic vocabulary is introduced with modeled pronunciation and animated illustrations. In contrast, the advanced sessions focus on more professional and practical topics including small talk, presentations, job interviews, traveling, customer service, and sales pitches.

This app operates in three steps. First, the user listens to the English native speaker, then repeats what he/she said, and the learner's own voice is recorded. Then users can compare how well they did. However, there is no feedback other than modeled pronunciation. Although many different languages are available for the tutorial, no bilingual support has been rendered in the exercise. Furthermore, the animated illustrations are too simple to clearly understand their meaning, and therefore, the app fails to keep users interested. Lastly, the pre-set sentences in the app are monotonous, decontextualized, and no platform is provided for sharing or monitoring one's learning progress. The interface is neat and clear, but only limited options for customizing are available.

4.1.7. BrainPOP Featured Movie. BrainPop Featured Movie provides daily animated films produced by BrainPOP, a well-respected educational organization. It contains a variety of topics and quizzes geared towards elementary school children in the upper grades. The movies it offers feature both auditory and visualized explanations with English subtitles, and demonstrates the academic subjects in an engaging manner. Related videos are provided next to the featured movie for users to go deeper into the topic if they are interested. Before and after viewing the movie, users can take quizzes to preview the main ideas and important details covered and check their understanding on what they have seen. It gives the user time to try again if the answer is not correct. Quiz results are saved so that users can monitor their progress. BrainPop's navigation is simple for users to find videos on particular topics, with large and brightly colored buttons for each subject area. While watching videos, users can pause, fast-forward, and rewind. Videos load quickly and have good sound quality. However, no interactive activities are bundled with this app, and content as well as functions are limited in the free version.

4.1.8. Summary and next step. After breaking down the components of each app, the apps are then evaluated. The evaluation focuses on the seven aspects as listed in the evaluation rubric: content quality, pedagogical coherence on language skills, feedback and self-correction, motivation, usability, customization, and sharing. Evaluation results are discussed in the next section. 


\section{Results and Discussion}

Seven selected apps were evaluated based on the rubric in Table 1. A review on each of the apps was conducted. A summary of the evaluation report for each application is provided below.

Table 3 shows the evaluation results of the selected language learning mobile apps. Three raters, one with a Ph.D. in instructional technology and two with Master's degrees in Teaching English to Speakers of Other Languages (TESOL), rated each app independently using the rubric in Table 2. Three raters' ratings were averaged to get the final rating for the apps in each criteria category.

Table 3. Evaluation Results of Selected Apps
The ranking of the evaluated apps is: Dulingo, Speaking English Fluently, YouDao Dictionary, VoiceTube, Shanbay Vocabulary, Speak English, and BrainPopFeaturedVideo.

The following section outlines the key descriptions of each app:

- Dulingo provides its novice users with extensive written lessons, as well as dictation and oral practice for its advanced users. It provides feedback and corrects the answers when users make mistakes. It also provides useful tips for learners to improve their language skills.

- Speaking English Fluently provides contextualized situations for languagelearning by allowing a user to immerse

\begin{tabular}{llllllll}
\hline & Dulingo & $\begin{array}{l}\text { Speaking } \\
\text { English } \\
\text { Fluently }\end{array}$ & $\begin{array}{l}\text { Youdao } \\
\text { Dictionary }\end{array}$ & VoiceTube & $\begin{array}{l}\text { ShanBay } \\
\text { Vocabulary }\end{array}$ & $\begin{array}{l}\text { Speak } \\
\text { English }\end{array}$ & $\begin{array}{l}\text { BrainPop } \\
\text { Featured } \\
\text { Movie }\end{array}$ \\
\hline $\begin{array}{l}\text { Content } \\
\text { Quality }\end{array}$ & 8 & $\mathbf{9 . 5}$ & $\mathbf{9 . 5}$ & 9.5 & 4 & 6.5 & 4 \\
\hline $\begin{array}{l}\text { Pedagogical } \\
\text { Coherence }\end{array}$ & $\mathbf{9}$ & $\mathbf{9}$ & 6.5 & 8 & 6.5 & 6 & 6.5 \\
\hline $\begin{array}{l}\text { Feedback and } \\
\text { Self-correction }\end{array}$ & $\mathbf{8}$ & 7 & 4 & 3 & $\mathbf{8}$ & 5 & 7 \\
\hline \begin{tabular}{l} 
Motivation \\
\hline Usability
\end{tabular} & 8 & $\mathbf{8 . 5}$ & 7 & 6.5 & 4 & 5 & 7.5 \\
\hline $\begin{array}{l}\text { Customization } \\
\text { Sharing }\end{array}$ & 3 & 2.5 & 4.5 & $\mathbf{8 . 5}$ & 3 & 4.5 & 3 \\
\hline $\begin{array}{l}\text { Total } \\
\text { (out of 70) }\end{array}$ & $\mathbf{5 0}$ & $\mathbf{4 7 . 5}$ & $\mathbf{4 6 . 5}$ & $\mathbf{4 6 . 5}$ & $\mathbf{3 6 . 5}$ & $\mathbf{3 6 . 5}$ & $\mathbf{3 6}$ \\
\hline
\end{tabular}


oneself in real life experiences. However, the app fails to provide learners with further instruction on how to correct and improve the unmatched words or phrases. As a result, learners who have failed many times in getting the correct answer may feel frustrated and unmotivated.

- Youdao Dictionary is a cloud-based app, so users can save their words and seamlessly synchronize their learning process on any available devices anytime. The cloud-embedded feature also provides books, forums, and classes for users to "discover" more in-depth content. Its navigation is sleek and simple. However, this apps provide limited assessment and motivation, and lacks interactive activities and monitoring mechanisms.

- VoiceTube, as its name suggests, is an app that users can learn English via YouTube videos. All content is classified into three levels: beginner, intermediate and advanced. The learning process is recorded and viewed in the form of charts. The app's navigation is clear. However, this app fails to offer any assessments and feedback for users to monitor their learning progress, and only a few options are available for sharing.

- In "Shanbay Vocabulary" users also can choose their daily learning plans. The vocabulary learning process has two phases, self-assessment mode, and quizzes. Its interface is simple and very easy to navigate. Users can form groups and join communities readily, where they can showcase their learning progress and carry out discussion with peers. However, no visuals are applied in learning.

- Speak English provides three steps for its users to follow. First, users listen to the English native speaker and then repeat what he/she said while recording. Users can compare how well they performed. However, there is no feedback other than modeled pronunciation for users to compare. Although many different languages are available for the tutorial, no bilingual support was rendered in the exercise. Furthermore, the animated illustrations are too simple to clearly get their meaning across, and therefore, fails to hold users' interest. Last, the preset sentences are monotonous as well as decontextualized, and no platform is provided for sharing or monitoring one's learning progress. The interface is neat and clear, but only limited options for customizing are available.

- BrainPopFeaturedMovie provides its users with daily movies containing both auditory and visualized explanations, in addition to English subtitles. Its navigation is simple, with large and brightly colored buttons for each subject area, making it easier for users to find videos on particular topics. However, no interactive activities are embedded in this app, and content and functions are limited for the free version.

In summary, this evaluation study incorporates a theory-driven rubric in order to assess the affordances of language learning apps for adult learners. The results show that there is no single language-learning app that could provide a one-size-fits-all solution to meet adult learners' language learning needs. However, this evaluation shows that mobile learning apps provide multiple channels and modalities for adult learners to practice language skills. Through careful instructional design, mobile apps can be integrated into language-learning modules or curriculum for adult learners to enhance their language skills. 


\section{Significance of the Study and Future Research}

The results in this paper contribute to the literature of mobile learning targeted at adult learners and elderly immigrants. The evaluation in this paper informs researchers and instructors in related fields, allowing them to develop in-depth and broad studies on the idea of incorporating mobile apps into ESL classroom and instructional design.

The research in this paper focuses on using linguistic theories to evaluate mobile apps. To explore more active and positive learning tools, it is necessary to apply the results from this study into practice to test the applicability of improving ESL learning outcomes for adult learners and elderly immigrants. Case studies can be conducted in subsequent research with elderly nonEnglish speaking immigrants using these apps. Feedback gained from the evaluation and case study can provide app developers with ideas in order to enhance their products to better meet users' learning styles and needs.

\section{References}

Abraham, L. B. (2008). Computer-mediated glosses in second language reading comprehension and vocabulary learning: A meta-analysis. Computer Assisted Language Learning, 21(3), 199-226.

Admiraal, W., Huisman, B., \& Pilli, O. (2015). Assessment in Massive Open Online Courses. Electronic Journal of e-Learning, 13(4), 207-216.

CAP Immigration Team. (2014). The Facts on immigration today. Retrieved from https://www.americanprogress.org/issues/ immigration/report/2014/10/23/59040/ the-facts-on-immigration-today-3/ on April 14, 2015.

Cavus, N., \& Ibrahim, D. (2009). M-Learning: An experiment in using SMS to support learning new English language words. British Journal of Educational Technology, 40(1), 78-91.

Chapelle, C. A. (2009). The relationship between Second Language Acquisition theory and computer assisted language learning. The Modern Language Journal, 93(s1), 741-753.

Cheung, W. S., \& Hew, K. F. (2009). A review of research methodologies used in studies on mobile handheld devices in K-12 and higher education settings. Australasian Journal of Educational Technology, 25(2), 153-183.

Eskey, M. T. A., \& Roehrich, H. (2013). Faculty observation model for online instructors: Observing faculty members in the online classroom. Online Journal of Distance Learning Administration, 16(2).

Golonka, E. M., Bowles, A. R., Frank, V. M., Richardson, D. L., \& Freynik, S. (2014). Technologies for foreign language learning: a review of technology types and their effectiveness. Computer Assisted Language Learning, 27(1), 70-105.

Hsu, C. K., Hwang, G. J., \& Chang, C. K. 
(2014). An automatic caption filtering and partial hiding approach to improving the English listening comprehension of EFL students. Educational Technology \& Society, 17(2), 270-283.

Hwang, G. J., \& Wang, S. Y. (2016). Single loop or double loop learning: English vocabulary learning performance and behavior of students in situated computer games with different guiding strategies. Computers \& Education, 102, 188-201.

Krashen, S. (1982). Principles and practice in second language acquisition. Oxford, NY: Pergamon.

Leach, M. (2009). America's older immigrants: A profile. Generations, 32(4), 343-49.

Lee, C. Y., \& Cherner, T. S. (2015). A comprehensive evaluation rubric for assessing instructional apps. Journal of Information Technology Education: Research, 14, 21-53.

Lin, C. C. (2014). Learning English reading in a mobile-assisted extensive reading program. Computers \& Education, 78, 4859.

Liu, G. Z., Hwang, G. J., Kuo, Y. L., \&Li, C. Y. (2014). Designing dynamic English: a

creative reading system in a context-aware fitness center using a smart phone and

QR-codes. Digital Creativity, 25(2), 169-186.

Liu, M., Navarrete, C., Maradiegue, E., \& Wivagg, J. (2014). Mobile learning and English Language Learners: A case study of using iPod touch as a teaching and learning tool. Journal of Interactive Learning Research, 25(3), 373-403.

Liu, M., Navarrete, C. C., \& Wivagg, J. (2014). Potentials of mobile technology for K-12 education: An investigation of iPod touch use for English Language Learners in the United States. Educational Technology \& Society, 17(2), 115-126.

Ma, Q., \& Kelly, P. (2006). Computer assisted vocabulary learning: Design and evaluation. Computer Assisted Language
Learning, 19(1), 15-45.

Reeves, T. (1994). Evaluating what really matters in computer-based education. In M. Wild and D. Kirkpatrick (Eds.), Computer education: New perspectives (pp. 219-246). Perth, Australia: MASTEC. Rodríguez, P., Nussbaum, M., \& Dombrovskaia, L. (2012). Evolutionary development: A model for the design, implementation, and evaluation of ICT for education programs. Journal of Computer Assisted Learning, 28(2), 81-98.

Sandberg, J., Maris, M., \& de Geus, K. (2011). Mobile English learning: An evidencebased study with fifth graders. Computers \& Education, 57(1), 1334-1347.

Smith, P.,\& Ragan, T. (2004). Instructional Design ( $3^{\text {rd }}$ ed.). Merill, MY: Wiley Jossey-Bass.

Halverson, R.,\& Smith, A. (2009). How new technologies have (and have not) changed teaching and learning in schools. Journal of Computing in Teacher Education, 26(2), 49-54.

Hargis, J., Cavanaugh, C., Kamali, T., \& Soto, M. (2014). A federal higher education iPad mobile learning initiative: Triangulation of data to determine early effectiveness. Innovative Higher Education, 39(1), 4557.

Hwang, G. J., \& Wu, P. H. (2014). Applications, impacts and trends of mobile technology-enhanced learning: a review of 2008-2012 publications in selected SSCI journals. International Journal of Mobile Learning and Organization, 8(2), 83-95.

Wilmoth, J. (2012), A demographic profile of older immigrant. Public Policy \& Aging Report , 22(2), 8-11

\section{Contact the Author \\ Xiaojun Chen}

Assistant Professor, School of Education, Department of Curriculum and Instruction, St. John's University

Email: chenx@stjohns.edu 